\title{
Experimental Observation of Resonance Effects in Intensely Irradiated Atomic Clusters
}

\author{
J. Zweiback \\ T. Ditmire \\ A. M. Rubenchik \\ A. Komashko \\ M. D. Perry \\ This paper was prepared for submittal to the \\ OSA 11th International Conference on Ultrafast Phenomena \\ Garmisch, Germany \\ July 12-17, 1998
}

July 10, 1998

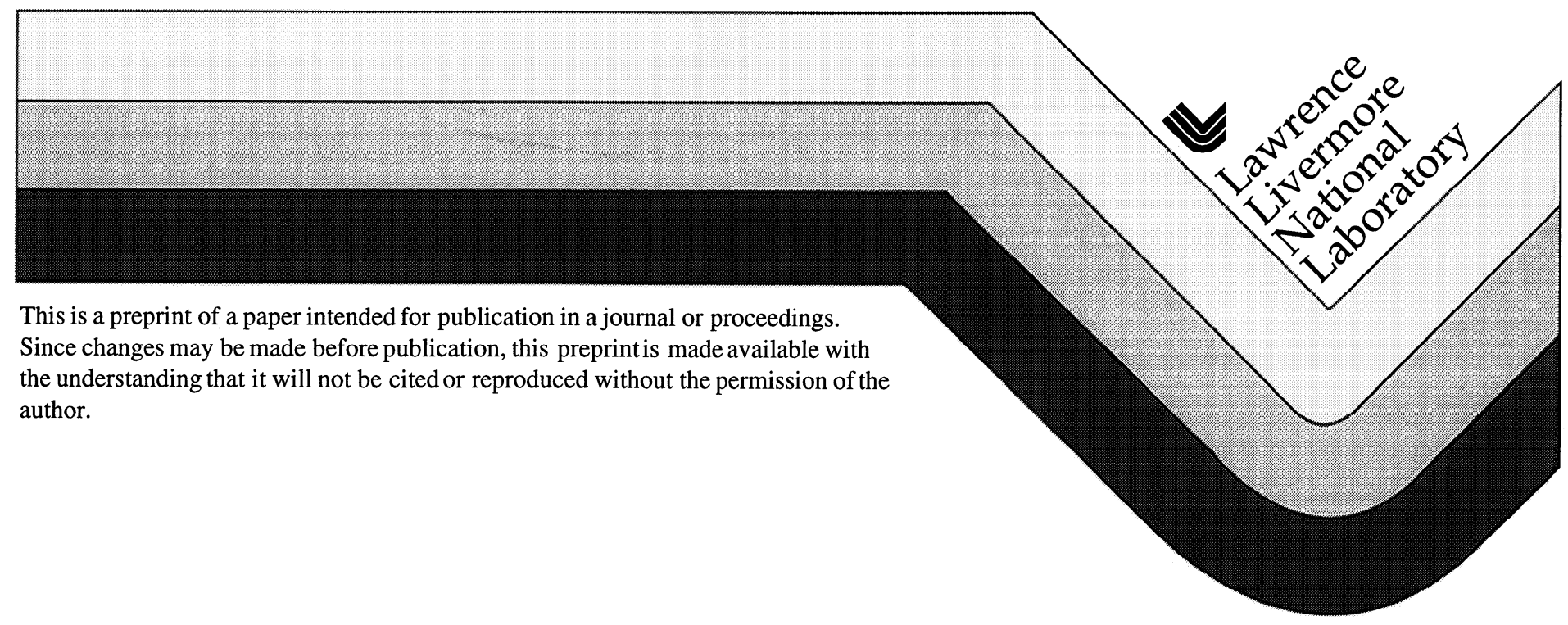




\section{DISCLAIMER}

This document was prepared as an account of work sponsored by an agency of the United States Government. Neither the United States Government nor the University of California nor any of their employees, makes any warranty, express or implied, or assumes any legal liability or responsibility for the accuracy, completeness, or usefulness of any information, apparatus, product, or process disclosed, or represents that its use would not infringe privately owned rights. Reference herein to any specific commercial product, process, or service by trade name, trademark, manufacturer, or otherwise, does not necessarily constitute or imply its endorsement, recommendation, or favoring by the United States Government or the University of California. The views and opinions of authors expressed herein do not necessarily state or reflect those of the United States Government or the University of California, and shall not be used for advertising or product endorsement purposes. 


\title{
Experimental Observation of Resonance Effects in Intensely Irradiated Atomic Clusters
}

\author{
J. Zweiback, T. Ditmire, A. M. Rubenchik, A. Komashko, M. D. Perry \\ Lawrence Livermore National Laboratory \\ PO Box 808, L-477 \\ Livermore, CA 94550, USA \\ Email: zweiback1@llnl.gov
}

\begin{abstract}
We have resolved the expansion of intensely irradiated atomic clusters on a femtosecond time scale. These data show evidence for resonant heating, similar to resonance absorption, in spherical cluster plasmas.
\end{abstract}

\section{Introduction}

There have been many studies of the irradiation of atomic clusters with short pulse high intensity laser radiation [1-4]. The high local density of cluster targets greatly increases the coupling of the laser energy to the atoms. Recent experiments [1,4] have examined the dynamics of cluster disassembly. Of particular interest is the time for disassembly and the heating mechanisms involved. Theory [3] predicts resonance effects should play a major role in these interactions. Similar to resonance absorption, this resonance should greatly enhance the absorption of laser energy by the clusters. Due to the spherical geometry of the clusters, the resonance occurs when the electron density is three times the critical density. In this paper we report on a series of experiments investigating these resonance effects

\section{Experimental Methods}

The laser used for these experiments was a Ti:Sapphire CPA laser system operating at a wavelength of $810 \mathrm{~nm}$, capable of producing about $50 \mathrm{~mJ}$ in a $50 \mathrm{fs}$ pulse [5]. We could vary the laser pulse length by changing the grating spacing in the compressor. The beam could also be directed through a beamsplitter, with one beam going into a variable delay leg. The beam was then focused with an $f / 3$ off axis paraboloid onto a cluster target. The clusters were produced by expansion in a supersonic Laval nozzle backed with up to 200 psi of xenon. From a calculation of the Hagena parameter we estimate the average number of atoms per cluster, $\mathrm{N}$, to be up to $6 \times 10^{5}[6,7]$. The cluster radii ranged from $85 \AA$ to $205 \AA$. The average density produced by the nozzle is estimated to vary from approximately 1.5 $\mathrm{x} 10^{17}$ to $6 \times 10^{17}$ atoms $/ \mathrm{cm}^{3}[8]$. 


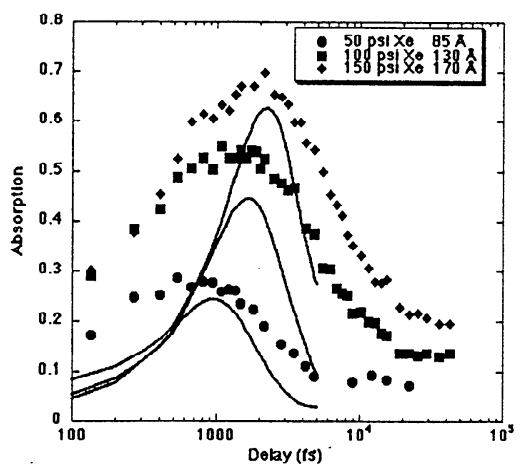

Fig. 1. Data from the pump probe experiments. Solid lines are model calculations.

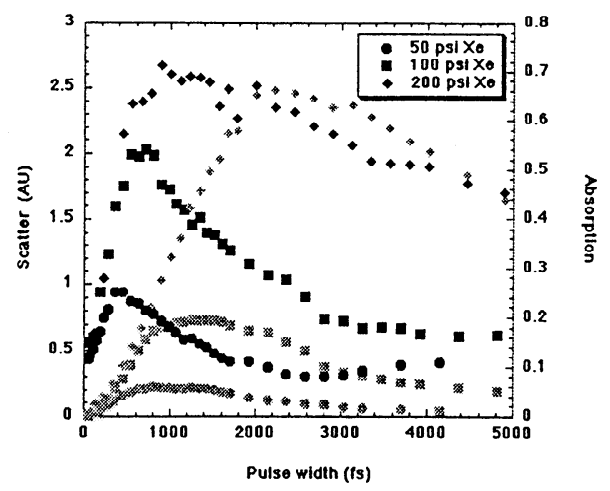

Fig. 2. Absorption (black) and Mie scattering (gray) measurements. Note that they peak for different pulse widths.

\section{Results and Discussion}

In the pump-probe experiments a small (10\%) pump pulse was sent into the target to expand the clusters before the probe pulse arrives. This allows us to probe the disassembly of the clusters as they expand into a bulk plasma. Both pulses were about $50 \mathrm{fs}$ in length. The probe pulse had a peak intensity in vacuum of $1.6 \mathrm{x}$ $10^{17} \mathrm{~W} / \mathrm{cm}^{2}$. Figure 1 shows absorption as a function of probe delay for different backing pressures of xenon. The absorption peak in Fig. 1 indicates the presence of resonant heating as the clusters expand. At very small delays, absorption is low; the cluster has little time to expand and the second pulse arrives long before the electron density reaches the resonance condition $\left(n_{e} / n_{\text {crit }}=3\right)$. However, as we increase the delay, absorption increases. The longer delay allows the electron density to be near the resonance condition when the pulse arrives, greatly enhancing the absorption of laser light. For longer delays, the cluster has continued to expand and the probe pulse is poorly absorbed by the, now underdense, plasma. Eventually, we reach a condition in which the clusters are fully disassembled and the absorption approaches a constant depending only on the average gas density. Our model, similar to Ref. [3], is shown as solid lines in Fig 1. The delay for peak absorption is in good agreement with the data.

Figure 2 shows that results of a simultaneous measurement of absorption and $90^{\circ}$ Mie scattering of the laser radiation for different pulse lengths. Clearly the scattering signal reaches a maximum at a longer pulse length than the absorption. As a cluster expands, not only does the electron density decrease, but the radius increase as well. For spheres of the relevant size, the ratio of scattering cross section to absorption cross section increases as radius increases [9]. This should cause the observed increase in scattering after the absorption has reached it peak 


\section{Conclusions}

In conclusion, we have resolved the expansion of atomic clusters on a femtosecond time scale. These data show that spherical resonance absorption plays an important role in cluster heating. The effects of resonance is seen in Mie scattering measurements also. However, the peak in the scattering occurs for longer pulse widths than absorption measurements.

Acknowledgments. This work was performed under the auspices of the U.S. Department of Energy by the Lawrence Livermore National Laboratory under contract W-7405-ENG-48.

\section{References}

1. T. Ditmire, E. Springate, J. W. G. Tisch, Y. L. Shao, M. B. Mason, N. Hay, J. P. Marangos, M. H. R. Hutchinson, Phys. Rev. A 57, 369 (1998).

2. J. Purnell, E. M. Snyder, S. Wei, A. W. Castleman Jr., Chem. Phys. Lett. 229, 333 (1994).

3. T. Ditmire, T. Donnelly, A. M. Rubenchik, R. W. Falcone, M. D. Perry, Phys. Rev. A 53, 3379 (1996).

4. M. Lezius, S. Dobosz, D. Normand, M. Schmidt, Phys. Rev. Lett. 80, 261 (1998).

5. P. Banks, J. Zweiback, S.N. Fochs, B.C. Stuart, M.D. Perry, in Conference on Lasers and Electro-Optics, Vol 91996 OSA Technical Digest Series (Optical Society of America, Washington, DC, 1996), paper CWI3.

6. O. F. Hagena and W. Obert, J. Chem. Phys. 56, 1793 (1972).

7. J. Wörmer, V. Guzielski, J. Strapelfeldt, T. Möller, Chem. Phys. Lett. 159, 321 (1989).

8. M. D. Perry, C. Darrow, C. Coverdale, J. K. Crane, Opt. Lett. 17, 523 (1992).

9. M. Kerker, The Scattering of Light and other Electromagnetic Radiation, (Academic Press, New York, 1969). 